\title{
Epigrafía de la Bética. Nuevos testimonios
}

\author{
Julián GONZÁLEZ FERNÁNDEZ \\ Universidad de Sevilla \\ julgonzalez@us.es
}

Recibido: 2 de abril de 2013

Aceptado: 20 de junio de 2013

\section{RESUMEN}

El autor presenta un total de dieciséis inscripciones, de ellas quince inéditas y una recuperada, procedentes de diversas ciudades privilegiadas de la provincia romana de la Bética: dos coloniae civium Romanorum (Italica, colonia Aelia, Urso, colonia Iulia Genetiva), una colonia Latina (Nabrissa Veneria), un municipium civium Romanorum (Gades, municipium Augustanum) y cinco municipia Latina Flavia: Irni, Iptuci (Prado del Rey, Cádiz), Arva y Canania (Alcolea del Río, Sevilla), Iptuci (Tejada la Nueva, Huelva), que sin duda contribuirán con su modesta aportación a mejorar el conocimiento que tenemos sobre ellas.

Palabras clave: Epigrafía latina. Baetica. Prosopografía latina. Ciudades romanas.

GonzÁlez Fernández, J., «Epigrafía de la Bética: nuevos testimonios», Cuad. Fil. Clás. Estud. Lat. 33.2 (2013) 253-280.

\section{Baetica Epigraphy. New Testimonies}

\begin{abstract}
The author presents a total of sixteen inscriptions, of which fifteen unreleased and one recovered from several chartered cities of the Roman province of Baetica: two coloniae civium Romanorum (Italica, colonia Aelia, Urso, colonia Iulia Genetiva), a Latin colony (Nabrissa Veneria), a municipium civium Romanorum (Gades, municipium Augustanum) and five Latin Flavia municipia: Irni, Iptuci (Prado del Rey, Cadiz), Arva and Canania (Alcolea del Río, Seville), Iptuci (Tejada la Nueva, Huelva), which no doubt will contribute with its modest contribution to improve the knowledge that we have about them..
\end{abstract}

Keywords: Latin Epigraphy. Baetica. Latin Prosopography. Roman towns.

GonzÁLez Fernández, J., «Baetica Epigraphy. New testimonies», Cuad. Fil. Clás. Estud. Lat. 33.2 (2013) 253-280.

Sumario 1. Municipium Flavium Irnitanum. 2. Vrso, colonia Iulia Genetiva. 3. Italica, colonia Aelia. 4. Nabrissa Veneria. 5. Iptuci. 6. Gades. 7. Arva-Canania. 8. Iptuci.

Es bien conocido por los estudiosos de la historia de la Hispania romana que los trabajos realizados para la reedición del CIL II, tanto en Museos de titularidad pública como en colecciones particulares, ha dado como resultado un notable incremento en el número de nuevas inscripciones, y no sólo de excepcionales documentos jurídicos, como la lex Irnitana, los ss.cc. de honoribus Germanici decernendis y de Cn. 
Pisone patre, el ius iurandum pro salute honore et victoria Augusti, la nueva tabla de la lex coloniae Iuliae Genetivae, etc, que están en la mente de todos, sino también de un número extraordinario de epígrafes de todo tipo, que pudiéramos cifrar en varios centenares.

En este trabajo presento un número reducido de inscripciones inéditas, en su mayoría funerarias, encontradas en diversos lugares de la Bética y que fueron visadas y fotografías por mí hace ya varios años en diversas colecciones privadas y que vienen a incrementar con su modesta aportación la información que tenemos sobre sus respectivas comunidades.

\section{MUNICIPIUM FLAVIUM IRNITANUM}

\section{1) INSCRIPCIÓN DE VALERIA CHRONIA?}

Placa de mármol blanco, partido en dos trozos, que adopta una forma casi triangular y que sólo ha conservado su margen superior cortado a bisel y con la parte posterior pulimentada; mide $21 \mathrm{~cm}$. de alto, entre $4-20 \mathrm{~cm}$. de ancho y $3 \mathrm{~cm}$. de grosor, la altura de las letras oscila entre 3,5 y $5 \mathrm{~cm}$ (1.1). Los puntos son triangulares. Fue encontrada, según me indicó su propietario, en una finca próxima al Molino del Postero, asentamiento del municipio Flavio Irnitano, al realizarse unas tareas agrícolas. Se encontraba en poder de un coleccionista particular en la localidad sevillana de Algámitas, donde la vi y fotografié en 1992 (lám.I):

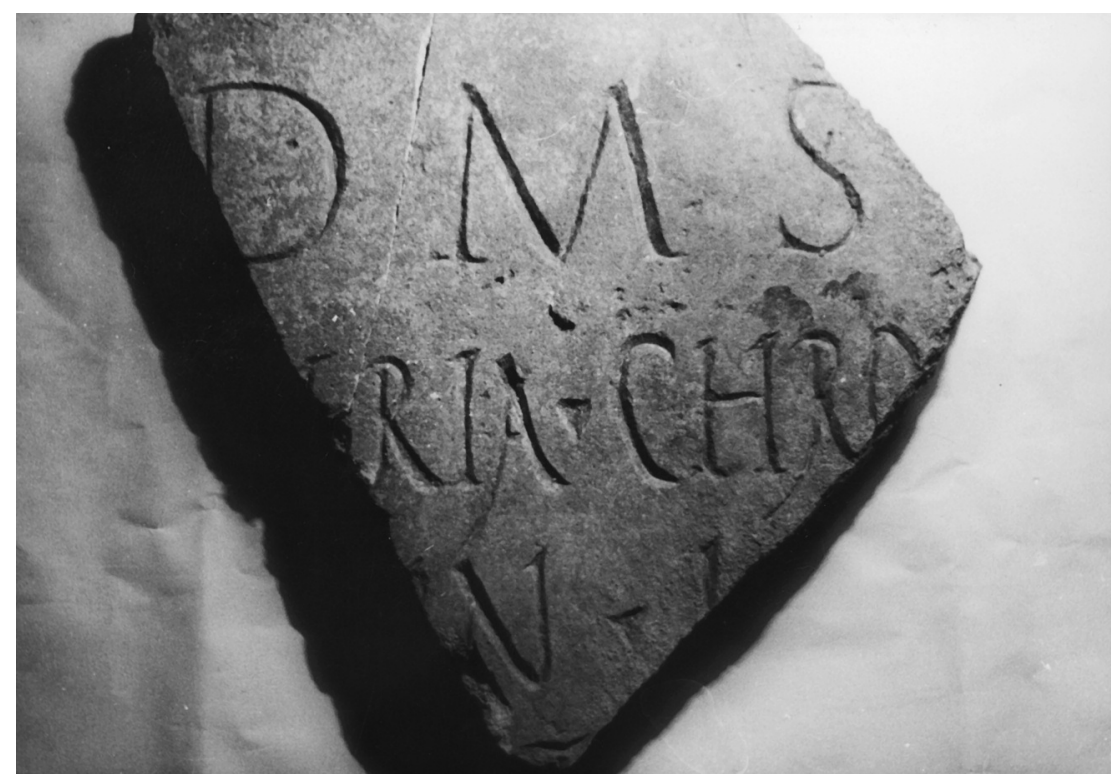

Lámina I. Inscripción de Valeria Chronia? 


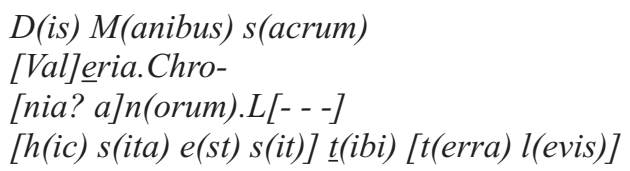

«Consagrado a los dioses Manes. Valeria Cronia?... de ...años.. aquí está enterrada. Sea para ti la tierra ligera».

La restitución de la parte perdida presenta algunos problemas por la ausencia de márgenes laterales, sin embargo, la parte conservada del nomen de la difunta-eria, nos lleva a pensar en nombres como Valeria, Laberia u otro similar, inclinándonos por el primero por la frecuencia del mismo en los registros epigráficos de la Bética. El cognomen con su $\mathrm{Ch}$ - inicial nos remite a nombres griegos $\mathrm{y}$, aunque tal radical no está atestiguado en las fuentes peninsulares, en Roma se documentan nombres como Chronia, Chrotis, etc. (Solin 2003, p.715, p.1117). En el ángulo inferior es posible ver un trazo horizontal, que he supuesto correspondería a una de las $\mathrm{T}$ de la fórmula S.T.T.L.

Las letras de la 1.1 son capitales cuadradas, de trazos elegantes, con el ángulo de la $\mathrm{M}$ ligeramente curvado; el resto son capitales actuarias, muy estilizadas, la $\mathrm{R}$ tiene el ojo pequeño y cerrado, la A con el trazo horizontal muy alto, la O ovalada, el izquierdo de la $\mathrm{N}$ apenas marcado, con lo que parece una $\mathrm{V}$, etc.

\section{- Comentario}

Se trata probablemente de una liberta, según se deduce de la ausencia de filiación y de su cognomen griego.

La gens Valeria tal vez sea la más representada en la epigrafía hispana, así, por citar un solo ejemplo, en la vecina colonia Genetiva tenemos atestiguados hasta cinco miembros de la misma. En cambio, el cognomen de la liberta no está recogido en los repertorios epigráficos.

La publicación de la lex Irnitana fue saludada con cierta sorpresa pues hasta ese momento no se tenían noticias documentales sobre la existencia de tal ciudad. Sin embargo, un examen más detenido sobre el emplazamiento de la misma nos muestra una realidad muy distinta. En efecto, el Molino del Postero, donde se encontraron las tablas de la ley y donde se ubica Irni, ocupa el centro de un triángulo cuyos vértices son las localidades de Algámitas (3 km. al noreste), El Saucejo (5 km. al suroeste) y Villanueva de San Juan (4 km. al noreste), por lo que, de la ausencia de noticias sobre la existencia de otra ciudad romana en esta zona, se puede deducir que las inscripciones encontradas en sus alrededores deben pertenecer a ciudadanos del municipio Flavio Irnitano.

Así, por ejemplo, de El Saucejo procede una tabula ansata que fue encontrada a finales del siglo XIX, en la que Q. Memmius Lupus ofrece, dona y dedica una exedra (CIL II 5449; CILA II,4 1202; HEp. 1860); de Villanueva de San Juan el epígrafe funerario de Manilia M.f. Chelido (CIL II 1422; CILA II,4 1205; HEp. 901) y de Algámitas la curiosa ara de Q. Sempronius Secundinus Baegensis, ofrecida por su madre Sempronia C.f. Rustica en su testamento y dedicada por su padre (o su abuelo, según 
Hübner) Sempronius Sempronianus Cembricinus (EE VIII 103, IX p. 91; CILA II,4 1203) y un riquísimo sello de bronce de P. Mussidius Sempronianus (CIL II 6259; CILA II,4 1204; HEp. 1884).

Con posterioridad al hallazgo de la lex Irnitana Antonio Caballos ha publicado el epígrafe funerario de una esclava de nombre Martina (HEp. 6, 1996, 877), encontrado en el propio Molino del Postero.

Así, pues, tendríamos atestiguados en Irni algunos de los nomina más habituales en la Bética, como los Sempronii, los Memmii, los Caecilii (los dos legati mencionados en la lex Irnitana), los Valerii y los Manilii, y otros no tanto, como los Mussidii, aunque su cognomen, Sempronianus, nos indica una estrecha relación familiar con los Sempronii.

Sin embargo y a pesar de los ya abundantes hallazgos epigráficos, faltaba por constatar epigráficamente el étnico Irnitano, circunstancia que, como veremos, se ha producido afortunadamente en una inscripción encontrada en Osuna de la que hablaré a continuación.

- Fecha: Probablemente siglo II d.C., según el tipo de letra.

\title{
2. VRSO, COLONIA IVLIA GENETIVA
}

\section{2) INSCRIPCIÓN DE SEMPRONIA SEVERINA?}

Fragmento de placa de mármol blanco, que sólo ha conservado sus márgenes superior y lateral derecho adoptando una forma casi triangular. Mide $15 \mathrm{~cm}$. de altura, $24 \mathrm{~cm}$. de anchura y $2 \mathrm{~cm}$. de grosor: la altura de las letras oscila entre 2 y 2,5 $\mathrm{cm}$.; los puntos son triangulares. Fue encontrado junto con los tres fragmentos siguientes en una reciente labor de limpieza realizado en la necrópolis de Urso, 1lamada de Las Cuevas. En la actualidad se encuentran depositados en el Museo Arqueológico de Osuna (lám. II):

\author{
$D($ is).M(anibus).s(acrum) \\ [Sem]pronia Se- \\ [veri]na? Irnit(ana) \\ [ann]or(um). $L X X$ \\ $5 \quad$ [pia i] $\underline{n} \mathrm{su}[\mathrm{is}]$ \\ [h(ic) s(ita) e(st) s(it) t(ibi) t(erra) l(evis)]
}

«Consagrado a los dioses Manes. Sempronia Severina, natural de Irni, de 70 años de edad, cariñosa con los suyos, aquí está enterrada. Que sea para ti la tierra ligera».

La restitución del nomen de la difunta está asegurada por el final - pronia y la presencia de dicha gens en el municipio Irnitano; en cuanto al cognomen, las partes conservadas Se...na me lleva a pensar en un nombre como Severina, ya que encaja con la parte perdida, en tanto que otros posibles como Semproniana, por ejemplo, resul- 


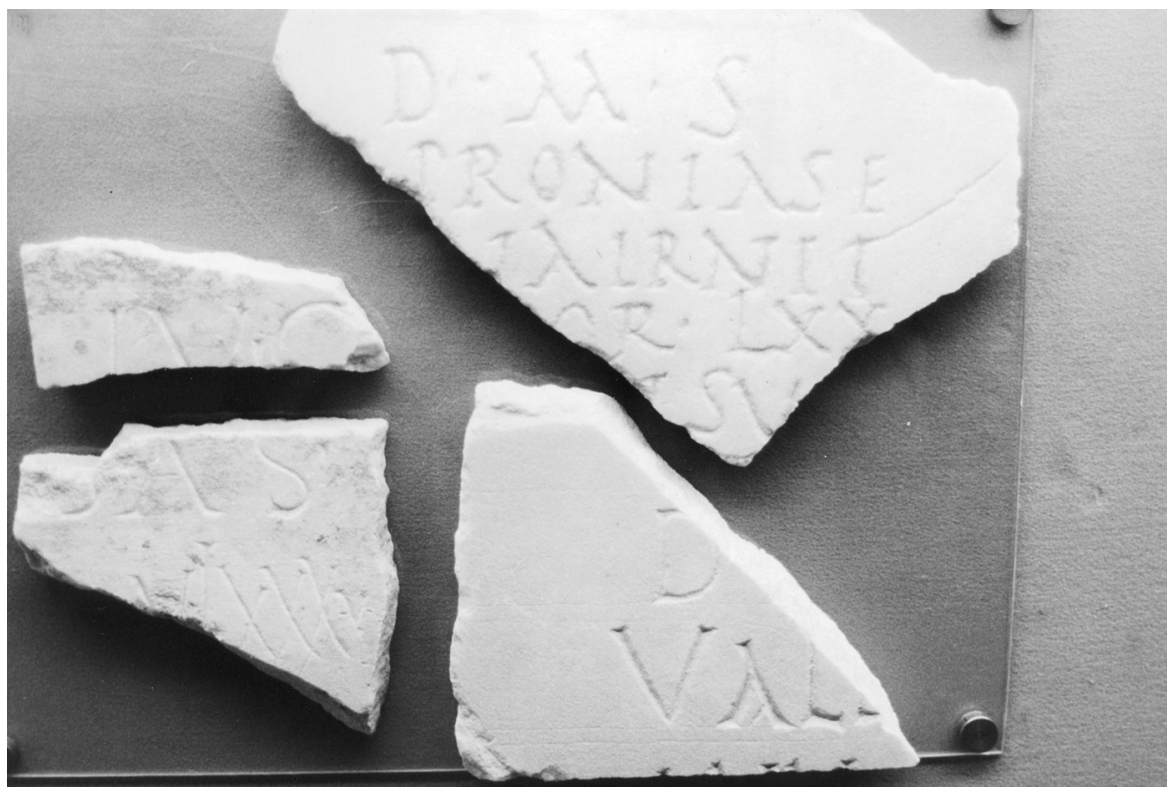

Lámina II. Fragmentos de inscripciones funerarias

tarían excesivamente largo. En la 1.5 se conserva parte de un trazo horizontal y la sílaba SV lo que inclina a pensar en la fórmula ritual pia in suis. Resulta muy probable que en la 1.6 figurasen las fórmulas rituales H.S.E.S.T.T.L, por lo que he preferido incluirlas en el texto del epígrafe.

Las letras son capitales actuarias, algo toscas, así, por ejemplo, los trazos izquierdos de la M, la N y la A salen del centro del opuesto, el ojo de la R es cerrado, la A carece de travesaño, los trazos horizontales de la E se inclinan hacia arriba y todas las letras tienen acusados remates. La puntuación es irregular, faltando entre nomen y cognomen, y entre éste y el étnico.

\section{- Comentario}

La gran novedad de este fragmento lo constituye sin duda la presencia del étnico Irnitana, por primera vez, fuera del texto de la lex municipi. La difunta pertenece a la familia Irnitana de los Sempronii, atestiguada en otros epígrafes del municipio, según ya he señalado.

La colonia Genetiva se extendía al noroeste de la actual Osuna, en una amplia zona donde aún pueden verse restos de la antigua muralla levantada por Pompeyo, de una calzada y de una necrópolis, llamada de Las Cuevas (Campos Carrasco 1989, pp.99111; Pachón Romero 2011, pp.187-222), en la Vereda de Granada, que contiene numerosos sepulcros excavados en las rocas y adornados con pinturas, cuya datación, según el tipo de ornamentos y pinturas, puede fijarse entre los siglo I a.C. y I d.C., donde fueron encontrados los fragmentos que presento. Estas pinturas, que recuer- 
dan las de las catacumbas romanas hicieron pensar a algunos estudiosos, sin mucho fundamento, en un carácter cristiano de las mismas (Thouvenot 1973, p.197; Wiseman 1956, p.197). Fuera del recinto de la ciudad en una pequeña colina, próxima a la Vereda de Granada se localiza el teatro.

Vrso fue una colonia civium Romanorum, denominada Genetiva Iulia, según confirman diversas inscripciones. El nombre de Vrso no aparece en la denominación de la colonia, según la costumbre antigua, pero sí lo hace en la expresión res publica Vrsonensium atestiguada en dos epígrafes del siglo III. Algunos estudiosos siguen pensado que los colonos de Vrso procedían de la plebe de Roma, lo que explicaría el cognomen Vrbanorum, que Plinio atribuye a la colonia, y confirmaría así el conocido pasaje de Suetonio que alude al asentamiento en las colonias de ultramar de 80.000 ciudadanos romanos (Caes. 42.1). Sin embargo, ya Mommsen advirtió que la expresión urbani se referiría a los incolae, y Brigitte Galsterer-Kröll cree que se trata simplemente de una aclaración de Plinio y no representa en modo alguno un título oficial. Además, conviene tener en cuenta que el apelativo urbanorum solo está testimoniado en Plinio (Nat.3.12) y en la lex de la colonia se la denomina colonia Iulia Geneti$v a$, por lo que tal vez Plinio esté haciendo referencia a que los colonos asentados formaran parte de una legión urbana, como, por ej. la legio V (Galsterer-Kröll 1972, pp.49-61; eadem 1975, p.124; Galsterer 1971, pp.8, 59; Leroux 1982, p.50).

Por otra parte, el testimonio de una inscripción ursaonense en la que se menciona a un centurión de la legión XXX, C. Vettius C.f. Ser. (CIL II 1404 = CILA II,3 620), parece apuntar más bien hacia una colonia militar de César. Conocemos la permanencia en Hispania de esa unidad, reclutada en Italia el año 49 a.C., que se encontraba en Hispania el 48 a.C. a las órdenes de Q. Cassius Longinus y en el 44/43 a.C. al mando de Asinius Pollio, que gracias al hallazgo de la nueva tabla de la ley, sabemos fue el deductor de la colonia (Caballos 2006). Con estos datos podemos fechar la inscripción en el periodo triunviral, es decir, una quincena de años después de la fundación de la colonia y todo parece indicar que un contingente de la legio $X X X$ participó en la fundación de la colonia Genetiva Iulia. La presencia en la misma de un centurión que fue IIvir iterum nos recuerda las palabras de Tácito (Ann.14.27) cuando echa de menos aquellos tiempos en los que se establecían legiones completas con sus tribunos, centuriones y legionarios, de modo que, con su unión y camaradería, constituían inmediatamente una auténtica comunidad.

La colonia recibió su territorio de las tierras confiscadas a los habitantes de la ciudad, decididos partidarios de la causa de Pompeyo, que se enfrentaron con notable firmeza a los ejércitos de César (Hisp.4). Los campos fueron asignados a los colonos en virtud de la lex Iulia agraria (lex Vrs. XCVII, 16: cui c(olonis) a (grorum) $d$ (andorum) a(tsignandorum) i(us) ex lege Iulia est.). Además, el cap. LIII de la lex Mamilia (Riccobono, FIRA I2 12), ley que no difiere de la lex Iulia agraria, está de tal modo presente en el cap. CIIII de la lex Vrsonensis que, lo que en aquella ley se dispone sobre el campo en general, aquí se repite con las mismas palabras sobre el ager coloniae.

- Fecha: segunda mitad del siglo II d.C., según el tipo de letra. 


\title{
3) INSCRIPCIÓN DE VALERIUS/-A
}

Fragmento de placa de mármol blanco, que ha conservado su margen lateral izquierdo y el ángulo superior del mismo lado, adoptando una forma trapezoidal, mide $13 \mathrm{~cm}$. de altura, $15,5 \mathrm{~cm}$. de anchura y 2,5 cm. de grosor; la altura de las letras oscila entre 3 y $3,5 \mathrm{~cm}$.; los puntos son triangulares. Fue encontrado junto con el anterior y los dos fragmentos siguientes en una reciente labor de limpieza realizado en la necrópolis de Urso, llamada de Las Cuevas. En la actualidad se encuentran depositados en el Museo Arqueológico de Osuna (lám. II):

\author{
$D$ (is) [M(anibus) s(acrum) \\ Vale $[$ rius/a - - -] \\ ann $[$ or $($ um) - - - ] \\ «Consagrado a los dioses Manes, Valerio (-a).. de ... años de edad...»
}

Las letras son capitales actuarias, de trazado profundo y dibujo regular, con acusados remates, el trazo de la A se inclina sin apoyarse en trazo izquierdo, la D y la V muy regulares. En la 1.3 se pueden ver los remates superiores de tres letras que hemos interpretado como ANN.

- Fecha: Por el tipo de letra podemos fechar este epígrafe en la primera mitad del siglo II d.C.

\section{4) FRAGMENTO INSCRIPCIÓN FUNERARIA}

Pequeño fragmento de placa de mármol blanco, del que sólo se han conservado unas pocas letras y que no conserva ninguno de sus márgenes, adoptando una forma casi rectangular, y mide $10,5 \mathrm{~cm}$. de altura, $13 \mathrm{~cm}$. de anchura y $2 \mathrm{~cm}$. de grosor; la altura de las letras oscila entre los $2 \mathrm{~cm}$. de la $\mathrm{V}$ del numeral y los $3 \mathrm{~cm}$. del resto; el punto es triangular. Fue encontrado junto con los dos fragmentos anteriores y el siguiente en una reciente labor de limpieza realizado en la necrópolis de Urso, llamada de Las Cuevas. En la actualidad se encuentran depositados en el Museo Arqueológico de Osuna (lám. II):

$$
\begin{aligned}
& {[--] \underline{S} A S .[---]} \\
& {[---\operatorname{an}] \underline{n}(\text { orum) - - - }] L X X X V[---]}
\end{aligned}
$$

Las letras son capitales actuarias, elegantes, con rasgos de la cuadrada en la 1.1, la $\mathrm{L}$ del numeral sobresale de la línea de caja y la $\mathrm{V}$ es más pequeña, probablemente por tratarse del final de la línea.

El final -sas, en su posición delante de la edad, debe corresponder al cognomen del difunto (o difunta), y nos recuerda los nombres griegos en - $\alpha \varsigma$, sin descartar la posibilidad de que se trate de un nombre indígena. 
- Fecha: Primera mitad del siglo II d.C., según el tipo de letra.

\section{5) FRAGMENTO INSCRIPCIÓN FUNERARIA}

Pequeño fragmento de placa de mármol blanco que tan sólo ha conservado parte de tres letras, adoptando una forma rectangular, y mide $4,5 \mathrm{~cm}$. de altura, $11 \mathrm{~cm}$. de anchura y $2,5 \mathrm{~cm}$. de grosor; la altura de las letras en su parte conservada es de $2 \mathrm{~cm}$; el punto es triangular. Fue encontrado junto con los tres fragmentos anteriores en una reciente labor de limpieza realizado en la necrópolis de Urso, llamada de Las Cuevas. En la actualidad se encuentran depositados en el Museo Arqueológico de Osuna (lám. II).

$$
\text { [- - - LV.CC(ara suis? - - ] }
$$

Las letras son capitales cuadras, muy elegantes. El punto entre $\mathrm{V}$ y $\mathrm{C}$ es muy claro, por lo que se trata de dos palabras diferentes, lo que nos ha llevado a pensar en el numeral de la edad, seguido de la fórmula afectiva cara suis.

- Fecha: segunda mitad del siglo I d.C., según el tipo de letra.

\section{ITALICA, COLONIA AELIA}

\section{6) INSCRIPCIÓN DE NICIAS}

Placa de mármol blanco, que ha perdido su parte inferior, así como pequeños trozos a lo largo de su perímetro, especialmente en su ángulo superior izquierdo, donde además muestra una profunda muesca que afortunadamente no afecta a lectura del texto. Mide (13) $\mathrm{cm}$. de altura, $22 \mathrm{~cm}$. de anchura y $3 \mathrm{~cm}$. de grosor; la altura de las letras oscila entre 2 y $2,3 \mathrm{~cm}$.; los puntos son hederae (1.1) y triangulares en las demás. Fue encontrada en 1988 en el cortijo El Aceitero, término de Salteras, al norte de las ruinas de Itálica; se encontraba en poder de un coleccionista particular de Sevilla, donde la vi y fotografié en 1985 (lám. III):

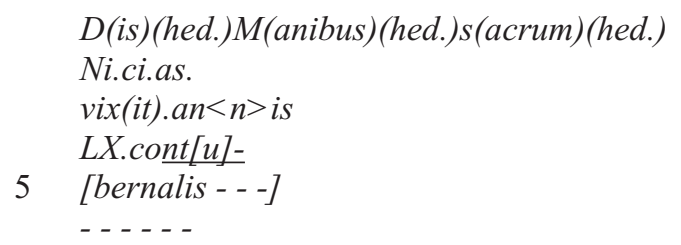

«Consagrado a los dioses Manes. Nicias vivió 60 años, su compañera...».

La paginación no está plenamente lograda y, aunque el lapicida ha procurado mantenerla, la L del numeral sobresale ligeramente, y en la izquierda las tres S mantie- 


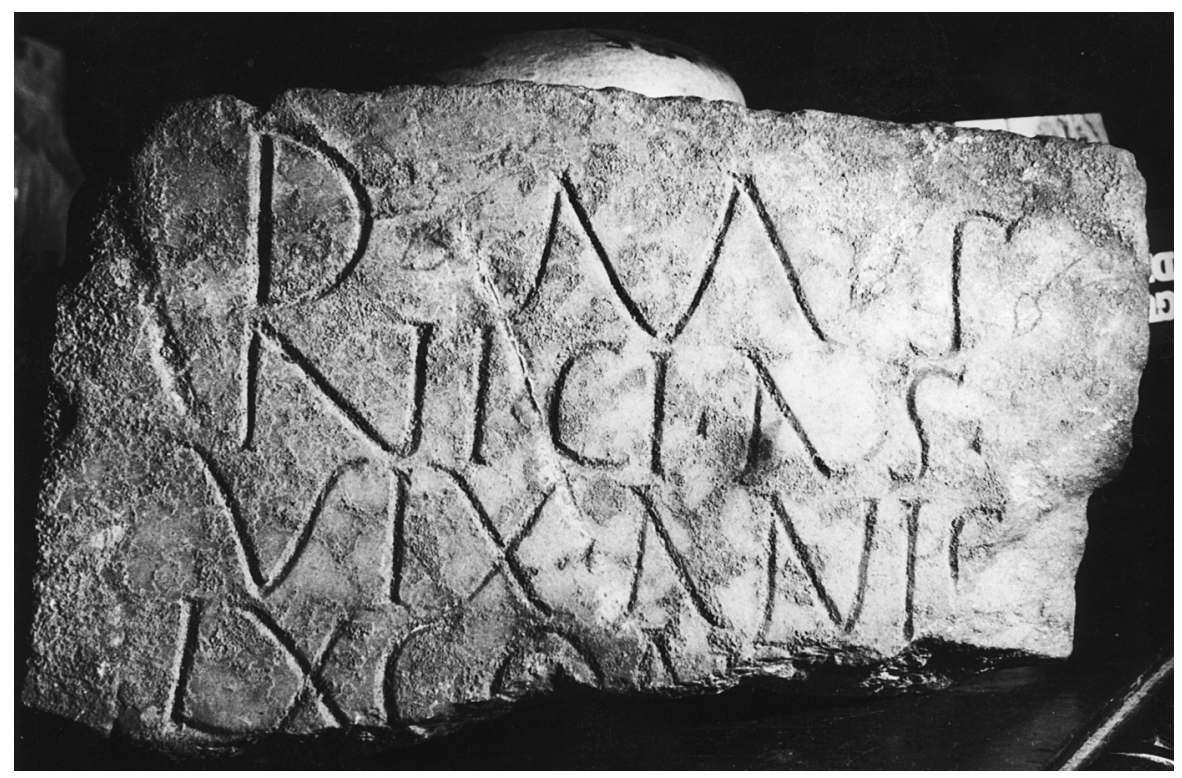

Lámina III. Inscripción de Nicias

nen posiciones diferentes. Las letras son capitales actuarias, de grabado profundo y forma irregular, aunque algunas de ellas, la D, la N, la L, intentan parecerse a la cuadrada; la $\mathrm{M}$ parece una $\mathrm{V}$ con dos trazos oblicuos a los lados, el cuerpo de la $\mathrm{S}$ es recto, el trazo izquierdo de la $\mathrm{V}$ se curva ligeramente hacia la derecha, la A carece de travesaño y el trazo izquierdo no nace en el extremo del derecho, etc. Hay puntuación irregular en el nombre Ni.ci.as, $y$ al final de las 11.1-2.

En el plano gramatical hay que señalar la simplificación del grupo -nn- en annis.

\section{- Comentario}

Se trata de un esclavo cuyo nombre griego, muy poco frecuente en la epigrafía peninsular, es prácticamente desconocido en la Bética. Probablemente con el vocablo contu[bernalis] se introduciría el nombre de la dedicante con las fórmulas funerarias habituales.

- Fecha: probablemente de finales del siglo II o primera mitad del III d.C., según el tipo de letra.

\section{7) INSCRIPCIÓN DE AELIA MARRUCINA}

Placa de mármol blanco, que conserva todos sus márgenes, aunque con ligeras erosiones en su contorno, lo que le confiere un aspecto algo irregular, adoptando una 
forma casi rectangular. Mide $13 \mathrm{~cm}$. de altura, $21 \mathrm{~cm}$. de anchura y $2 \mathrm{~cm}$. de grosor; la altura de las letras oscila entre 1,5 y $2 \mathrm{~cm}$.; los puntos son pequeñas virgulae (1.1) y triangulares en las demás. Fue encontrada en las proximidades de Itálica, sin que su actual propietario haya querido facilitarme más datos sobre la fecha y las circunstancias de su hallazgo. Se encontraba en poder de un anticuario en Sevilla, donde la vi y fotografié en 1986 (lám. IV):

$\begin{array}{ll} & \text { D(is).M(anibus).s(acrum) } \\ & \text { Aelia.Marrucina } \\ & \text { vixsit.annis.XXXVIII } \\ & \text { pia.in.suis } \\ & h(\text { ic).s(ita).e(st).s(it).t(ibi).t(erra).l(evis) }\end{array}$

«Consagrado a los dioses Manes, Elia Marrucina vivió 38 años, cariñosa con los suyos, aquí está enterrada. Sea para ti la tierra leve».

El diseño del texto ofrece cierto desorden, así, por ejemplo, todas las líneas siguen la paginación izquierda, incluso la fórmula D.M.S., que debería haber estado centrada; en cambio, la derecha sigue la paginación en las 11.2-3, pero en las 11.3-4 se limita a escribir las fórmulas rituales, sin prolongarlas hasta el final de la línea, con lo que se consigue un ordenamiento secundario, al coincidir con el final de la 1.1. Además, como si el lapicida tuviese problemas para seguir la línea recta, la parte izquierda del texto se inclina ligeramente a la izquierda y el derecho hacia el mismo lado. Las letras son cuadradas actuarias, de grabado tosco y formas irregulares, así,

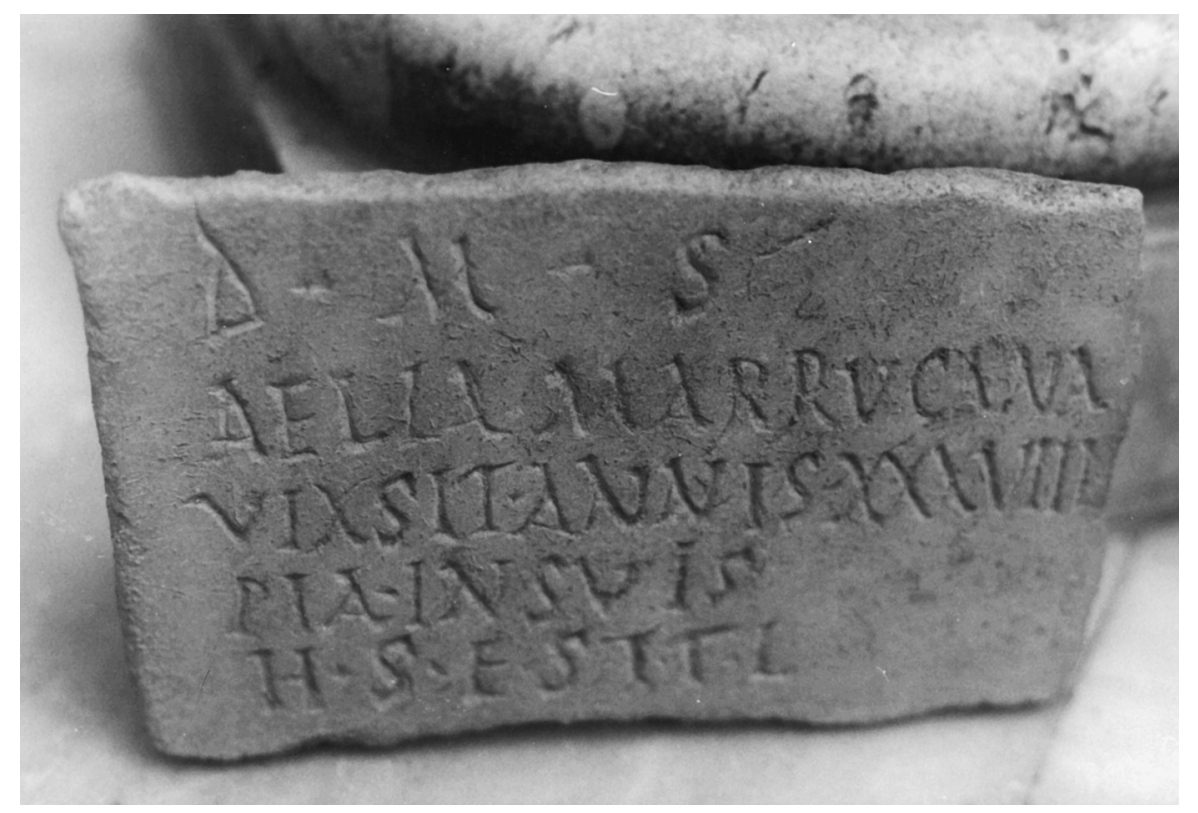

Lámina IV. Inscripción de Aelia Marrucina 
el trazo izquierdo de $\mathrm{M}, \mathrm{N}$, A nace del centro del derecho, el travesaño de la A se omite o cruza el trazo izquierdo, la $\mathrm{N}$ parece una $\mathrm{V}$ con un trazo inclinado, el ojo de la $\mathrm{R}$ está cerrado, etc.

En el plano gramatical hay que anotar la grafía vixsit, forma ultracorrecta para reflejar la doble pronunciación de la letra $-x$ -

\section{- Comentario}

El nomen de la difunta Aelia es muy frecuente en la onomástica bética y en especial en la propia Itálica, sin que ello signifique que se trate de una pariente del emperador Adriano. El cognomen Marrucina ${ }^{1}$ es evidentemente un étnico y corresponde a los marrucini, una de las tribus que habitaba en la Italia central en las costas del mar Adriático y es nuevo en la onomástica peninsular, pues tan sólo conocemos un ejemplo en la propia Roma (CIL VI 26280: Marrucinus; Kajanto 1965, p.185).

La presencia en Itálica de una marrucina nos lleva a plantearnos, siquiera sea como una hipótesis de trabajo, si la difunta no será una descendiente de los primeros colonos dejados allí por Escipión. Los marrucini fueron fieles aliados de Roma en la segunda Guerra Púnica, formando parte el 225 a.C. de un escuadrón de caballería de cuatro mil jinetes junto a Marsi, Vestini y Frentani, por lo que la presencia de un contingente de marrucini en el ejército de Escipión no parece extraño, ni tampoco que alguno de ellos formase parte de los soldados de las tropas itálicas heridos dejados por éste en Itálica. No olvidemos que Hadria la ciudad del Piceno de donde procedían los ancestros de Adriano se encuentra a poco más de $15 \mathrm{~km}$. de Teate (hoy Chietti) la capital de los marrucini. Esta hipótesis me parece sugerente, por lo que, con las naturales reservas, considero que muy bien pudiera tratarse de una descendiente de alguno de aquellos soldados itálicos fundadores de Italica.

- Fecha: probablemente de la segunda mitad del siglo II o primera del III, según el tipo de letra.

\section{NABRISSA VENERIA}

\section{8) INSCRIPCIÓN DE NOTHUS}

Placa de mármol blanco, en buen estado de conservación, pues ha conservado todos sus márgenes, mide $13 \mathrm{~cm}$. de altura, $22 \mathrm{~cm}$. de anchura y $3,5 \mathrm{~cm}$. de grosor; la altura de las letras oscila entre 2 y $2,5 \mathrm{~cm}$.; los puntos son triangulares. Fue encontrada en los alrededores de Lebrija sin que hayamos podido determinar ni el lugar exacto ni la fecha del mismo; en la actualidad forma parte de la colección de Don Enrique Cortines en el cortijo Micones de dicha localidad, donde la he visto y fotografiado en 1996 (lám. V):

1 No Marrucana, como por error pudiera hacer pensar la fotografía. 


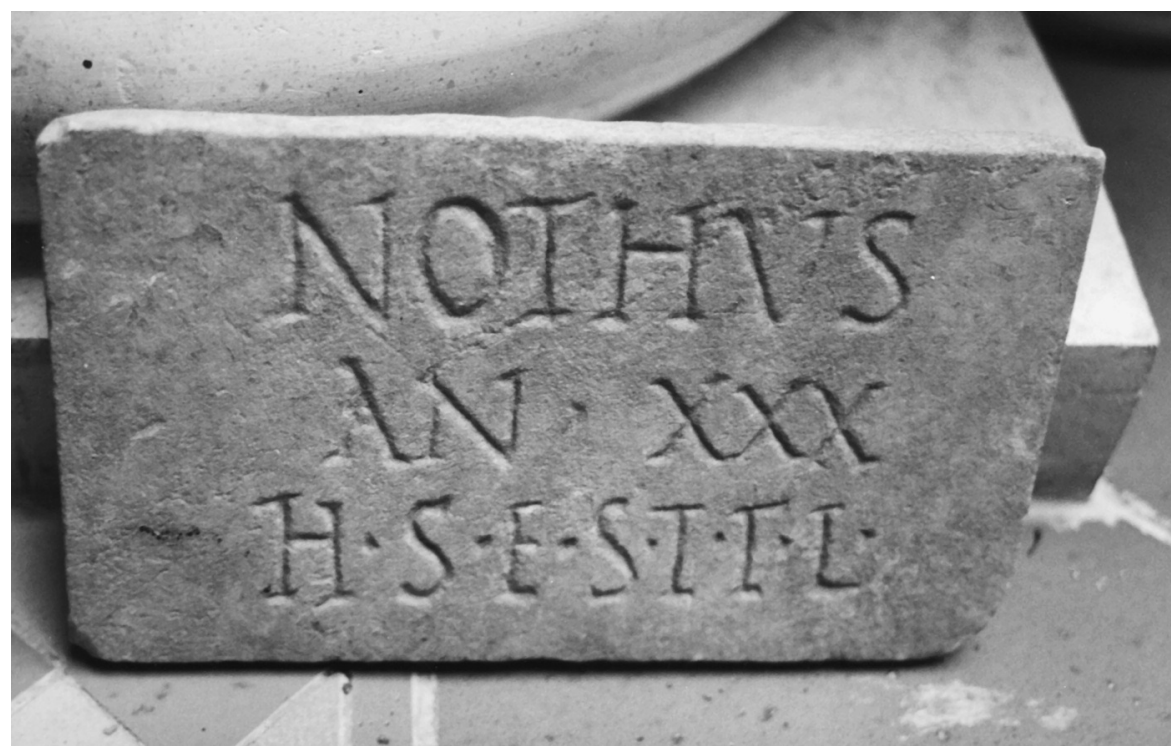

Lámina V. Inscripción de Nothus

Nothus

an(norum). $X X X$

$h($ ic).s(itus).e(st).s(it).t(ibi).t(erra).l(evis).

«Noto, de 30 años de edad, aquí está enterrado. Sea para ti la tierra ligera».

Las letras son capitales cuadradas, algo toscas y de acusados remates en algunas letras, especialmente en la $\mathrm{H}$ de la fórmula funeraria; el trazo izquierdo de la $\mathrm{A}$ nace en el centro del derecho, los travesaños de la E con rectos y cortos, etc. Hay puntuación al final de la 1.3. La distribución del texto está muy cuidada.

\section{- Comentario}

Se trata sin duda de un esclavo, cuyo nombre, de origen griego, está atestiguado en inscripciones de Singilia Barba y Olisippo (CIL II2/5, $805=$ HEpOl. 2, 1990, 460; HEpOl. 3056; CIL II 196 (p 692) = HEp. 21285) y en su variante femenina, Nothis, en sendas inscripciones de Clunia $(A E 1988,769)$ y en el cognomen de la conocida secunda mima enterrada en Augusta Emerita (HEpOl. 5, 1995, 97).

La localización de Nabrissa cognomine Veneria (PLIN.N.H.3.1.10) en la moderna Lebrija es cuestión unánimemente aceptada (Tovar 1974, pp.147-48; Galsterer-Kröll 1975, pp.124,128; Sillierès 1990, pp.729-31), y no existe ningún fundamento para la duda expuesta por Galsterer (1971, p.21, n.43, que además lee mal: «des populus von Conobasa»), pues de la inscripción CIL II 1294, con la expresión ex consensu populi Conoba(riae), aducida por éste como argumento, no se dice que fuera encontrada en Lebrija, sino que estaba 'pro foribus domus Alonsi Pasqualis', además la ads- 
cripción del homenajeado a la tribu Quirina hace imposible su atribución a Lebrija, como ya viera el propio Hübner (CIL II 1294: «potest titulus hic Nabrissam allatus esse ex situ quodam vicino»).

Sobre el status de Nabrissa tan sólo sabemos con certeza que era una ciudad privilegiada ya desde César (Galsterer-Kröll 1975, pp.123-125), en todo lo demás tan sólo hay hipótesis, así Thouvenot, al igual que Corzo-Jiménez la consideran un $m u$ nicipium iuris Latini; Galsterer acepta implícitamente que se trataba de un municipium civium Romanorum, al rechazar la afirmación de la Henderson de que algunos municipios de época augustea habían sido antes colonias latinas. Tovar duda entre un oppidum Latinorum aut civium Romanorum «weder ein municipium noch eine Kolonie», según la opinión de Detlefsen.

Grant $(1969$, pp. 217, 473) atribuye a Nabrissa un semis con leyenda CVIN, que él desarrolla como c(olonia) V(eneria) I(ulia) $N($ abrissa); este parecer ha sido rechazado por el matrimonio Galsterer (1971, p.21.nn.46-47; 1975, p.124.n.24), que opinan que puede tratarse de Carthago Nova, aunque las emisiones de esta ciudad llevan siempre la leyenda $C V I N C$ (o $K$ ), como el propio Grant ha hecho notar, y añade que estas monedas se encontraban frecuentemente en el sur de España, no en los alrededores de Cartagena. Por ello, nos inclinamos a aceptar el parecer de Grant, aunque con la reserva de que no se trataba de una colonia Romana sino de una Latina, según he defendido ya en anteriores trabajos, siguiendo el parecer de la Henderson (González 1984, p.29).

- Fecha: Probablemente la segunda mitad del siglo II d.C., según el tipo de letra.

\title{
9) INSCRIPCIÓN DE HERENNIA APRA
}

Placa de mármol blanco veteado, con el texto enmarcado en un cuadro inciso en el mármol, con los bordes rebajados y pulimentada en la parte posterior. Mide $30 \mathrm{~cm}$. de alto, 49,50 de ancho y $2 \mathrm{~cm}$. de grosor; la altura de las letras oscila entre los 3,5 y los $3 \mathrm{~cm}$; los puntos con vírgulas en la 1.1 y redondos en las demás. Fue encontrada en los alrededores de Lebrija sin que haya podido determinar ni el lugar exacto ni la fecha del mismo, habiendo llegado al conocimiento de la misma gracias a la amabilidad del Dr. Antonio Caro Bellido (†), que me facilitó la fotografía que adjunto (lám. VI):

\author{
D(is).M(anibus).s(acrum) \\ Herennia.Apra \\ Emerit(ensis).an(norum).XXXVII \\ mater fecit \\ $5 \quad h(i c) \cdot s($ ita).e(st).s(it).t(ibi).t(erra).l(evis).
}

«Consagrado a los dioses Manes. Herenia Apra, natural de Mérida, de 37 años de edad, su madre le dedicó (este epígrafe), aquí está enterrada. Sea para ti la tierra ligera».

La paginación es desordenada en ambos márgenes, aunque parece que el lapicida ha intentado organizar el texto en torno a un eje central. Las letras son capitales cuadradas, toscas y de trazado irregular, algunas con ligera inclinación hacia la derecha, los tra- 


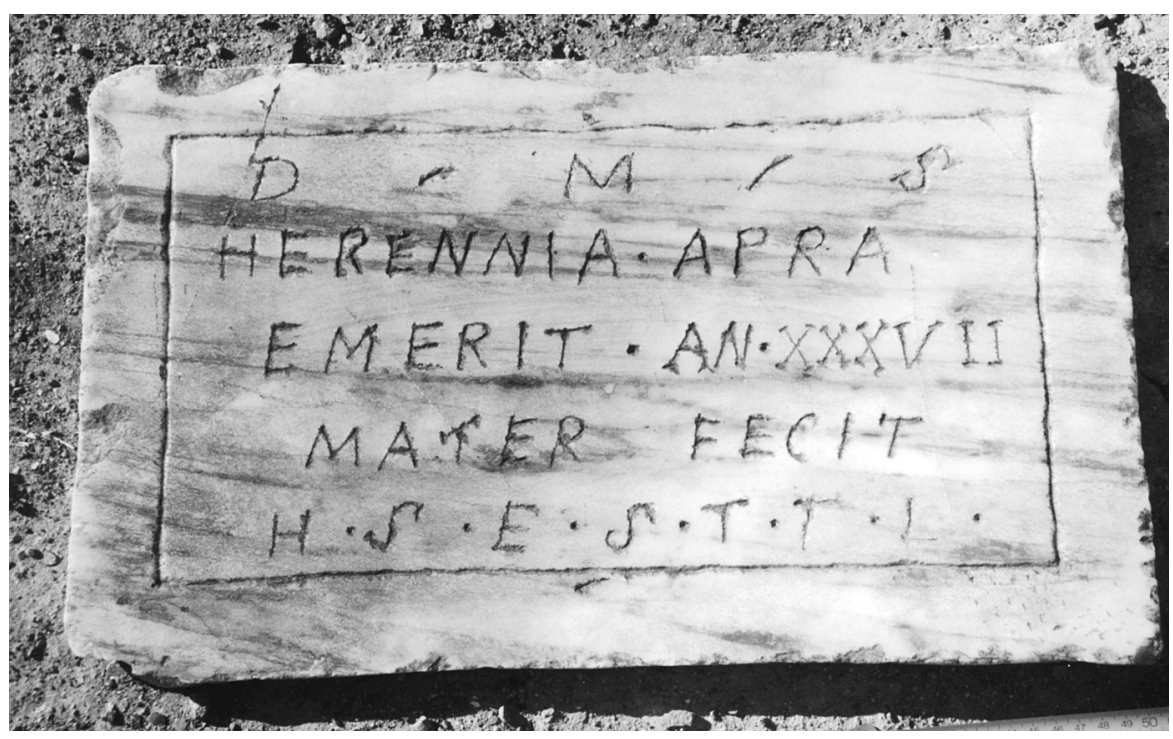

Lámina VI. Inscripción de Herennia Apra Emeritensis

zos horizontales se inclinan hacia arriba, los ojos de la $\mathrm{P}$ y $\mathrm{R}$ cerrados, el ángulo de la M corto no alcanza la línea de la caja, etc. Hay puntuación irregular al final de la 1.5.

\section{- Comentario}

El nomen Herennia es muy común en la epigrafía peninsular, especialmente en la Bética, y ya conocido en la propia Nabrissa (CIL II 1296; CILA II, 1002: Herennia Clodiana), aunque la difunta haga constar su origen Emeritense; en cambio su cognomen Apra, obtenido de la flora y la fauna, es muy frecuente en la onomástica latina con más de 200 testimonios (Kajanto 1965, p.325), aunque sólo lo conozcamos en una inscripción encontrada en la colonia Genetiva Iulia (CIL II2/5, 1029 = CIL II $5443=$ CILA II,3 626).

- Fecha: Probablemente segunda mitad del siglo II d.C., según el tipo de letra.

\section{0) FRAGMENTO DE INSCRIPCIÓN FUNERARIA}

Parte inferior de un ara de mármol blanco, que ha conservado la molduras y sólo dos líneas de texto; mide $16,5 \mathrm{~cm}$. de altura, $31 \mathrm{~cm}$. de anchura y $17 \mathrm{~cm}$. de grosor; la altura de las letras es de $2,5 \mathrm{~cm}$. Fue encontrada en Lebrija en circunstancias y fecha que desconocemos y en la actualidad forma parte de la colección de don Enrique Cortines en su cortijo de Micones en Lebrija, donde la vi y fotografié en 1990 (lám. VII): 


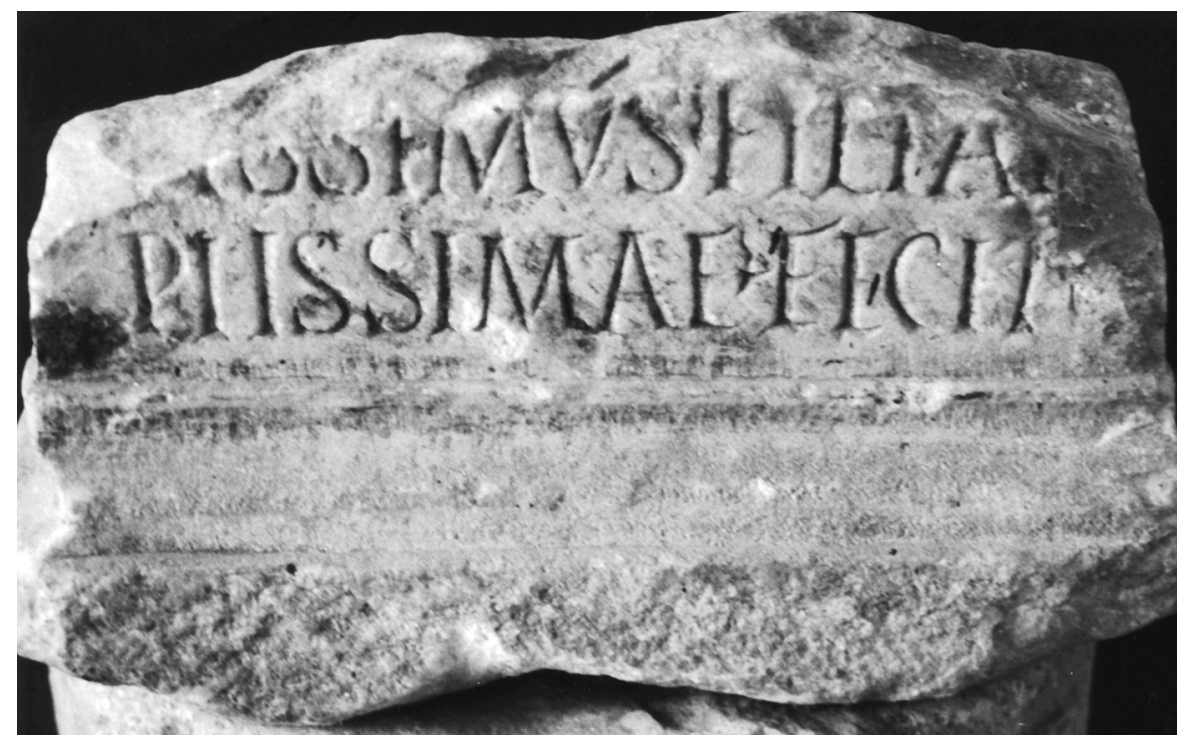

Lámina VII. Fragmento de inscripción funeraria

\section{[pater desideran-] \\ [t] issimus(hed.)filiae \\ piissimae(hed.)fecit}

«... un padre amantísimo hizo (este monumento) para una hija cariñosísima».

Las letras son capitales cuadras elegantísimas, con los remates de la $\mathrm{S}$ algo redondeados, el interior de la $\mathrm{E}$ y $\mathrm{F}$ más pequeño y menos marcado que los demás, el trazo horizontal de la A centrado, etc. Los puntos son hederae.

- Fecha: Según el tipo de letra y la elegancia de su ejecución podríamos fecharla en la primera mitad del siglo II.

\section{1) FRAGMENTO}

Placa de mármol negro, veteado, que no ha conservado ninguno de sus márgenes, mide $14 \mathrm{~cm}$. de altura, $17 \mathrm{~cm}$. de anchura y $9 \mathrm{~cm}$. de grosor; la altura de las letras es de 7,5 cm. Fue encontrada en Lebrija en circunstancias y fecha que desconocemos y en la actualidad forma parte de la colección de don Enrique Cortines en su cortijo Micones en Lebrija, donde la vi y fotografié en 1990 (lám. VIII):

$$
\text { [- - muni]cip[ium - - -] }
$$




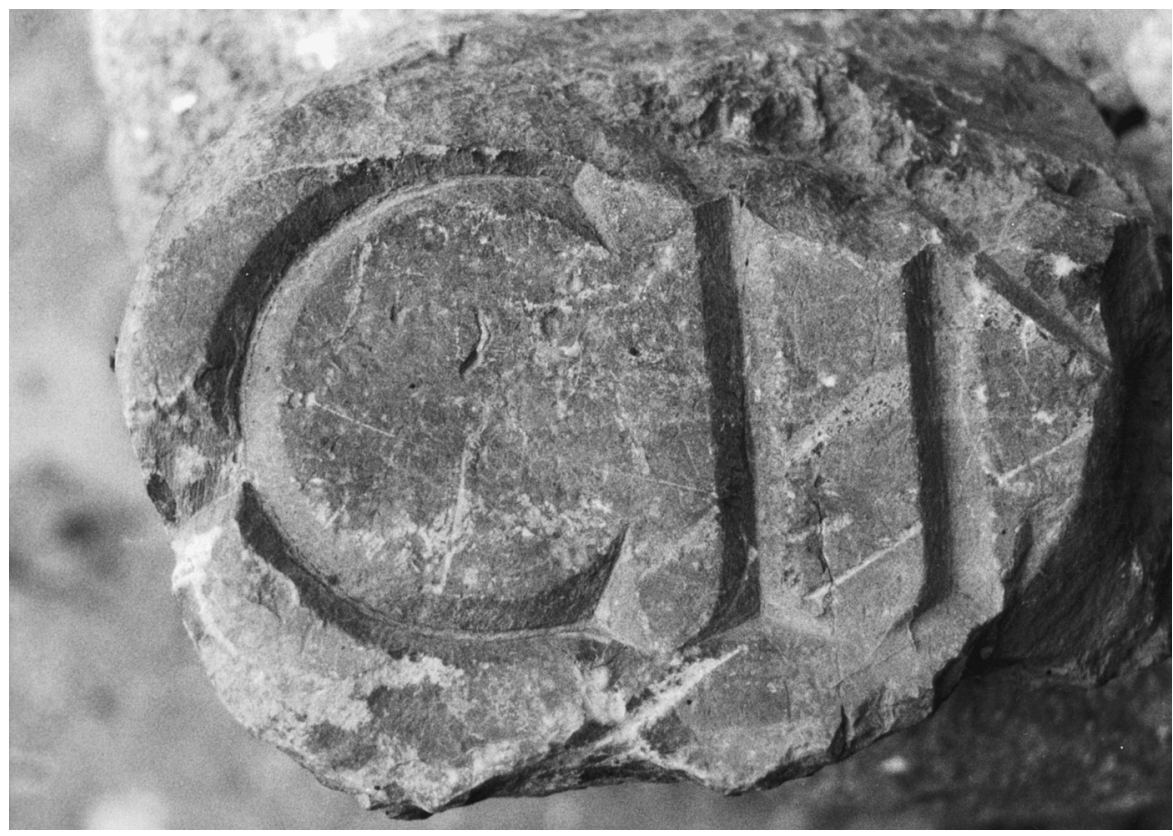

Lámina VIII. Fragmento de inscripción monumental

Las letras son capitales cuadras, de espléndida factura, en relieve, lo que indica sin ningún género de dudas que se trata de una inscripción pública, y aunque desgraciadamente el escaso texto impide una lectura siquiera sea aproximada, no me resisto a pensar en una palabra como [muni]cip[ium].

- Fecha: seguramente primera mitad del siglo I d.C., según el tipo de letra.

\section{2) INSCRIPCIÓN DE IULIUS SOPHRO}

Bloque de mármol blanco, que ha sufrido pérdidas en sus ángulos inferiores, así como a lo largo de su perímetro, además la superficie está muy erosionada hasta el punto de leerse el texto con gran dificultad, mide en sus puntos de mayor extensión $56 \mathrm{~cm}$. de altura, $59 \mathrm{~cm}$. de anchura y su grosor oscila entre 12 y $17 \mathrm{~cm}$.; los signos de puntuación son redondos. Esta inscripción fue recogida por Velázquez y Masdeu en el siglo XVIII y de éstos por Hübner, posteriormente se perdió y recientemente fue encontrada de nuevo junto a la llamada Puerta del Aceituno o de Rota, una de tres puertas romanas documentadas (CIL II 1297; CILA II 4 1003). En la actualidad forma parte de la colección de don Enrique Cortines en su cortijo de Micones en Lebrija. Debo la información, así como la fotografía que incluimos, a la amabilidad del profesor Antonio Caro Bellido (†) (lám. IX): 


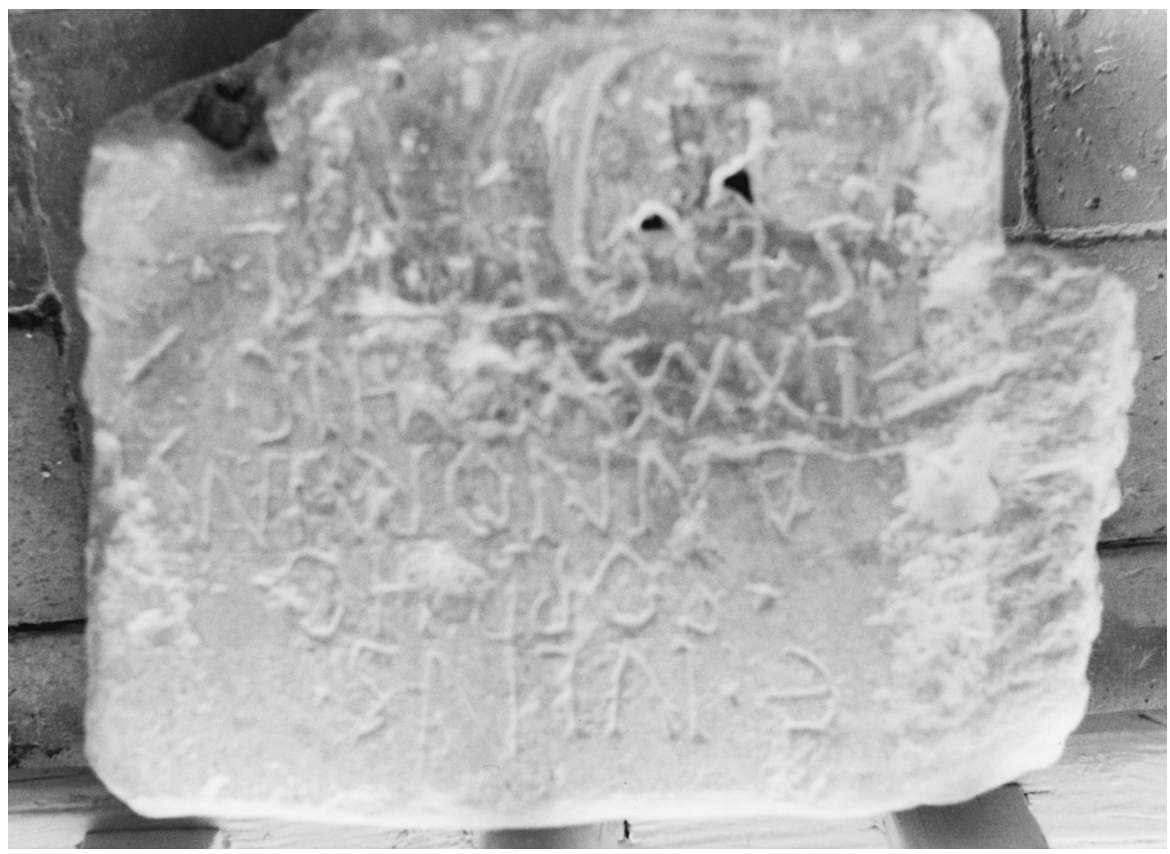

Lámina IX. Inscripción de C. Iulius Sophro

G(aius).Iulius.

Sophro.

annorum.

.LXXXVI.hic.

5 .s(itus).e(st).s(it).t(ibi).t(erra).l(evis). gera».

«Gayo Julio Sofrón, de 86 años de edad, aquí está enterrado. Sea para ti la tierra li-

Los márgenes no obedecen a paginación alguna, y así, por ejemplo, la -M de annorum está fuera de la línea. Las letras son capitales cuadradas, de trazado algo tosco $\mathrm{y}$ desigual, la $\mathrm{C}$ del praenomen parece una $\mathrm{E}$, pues tiene un trazo horizontal, la $\mathrm{O}$ ligeramente ovalada, los trazos horizontales con cierta inclinación hacia arriba, el ojo de la $\mathrm{R}$ abierto, etc. Tiene puntuación irregular al final de todas las líneas y al principio de las 2, 4-5.

\section{- Comentario}

Es el primer testimonio en la epigrafía de Nabrissa Veneria de un C. Iulius, circunstancia sorprendente si tenemos en cuenta que la fundación de la misma se atribuye a Julio César. El cognomen griego del difunto, Sophro, así como la ausencia de filiación nos lleva a pensar que probablemente se trataría de un liberto. 
- Fecha: La datación más aproximada es la de finales del siglo II o principios del III, según el tipo de letra.

\section{IPTUCI}

\section{3) INSCRIPCIÓN DE L. POSTUMIUS OPTATUS}

Placa de mármol blanco en muy buen estado de conservación, pues sólo ha perdido pequeñas lascas en su perímetro, mide $37 \mathrm{~cm}$. de altura, $44 \mathrm{~cm}$. de anchura y $3 \mathrm{~cm}$. de grosor; las letras oscilan entre 5,2 y $6 \mathrm{~cm}$. (1.2 $\mathrm{S}=9 \mathrm{~cm}$.; $\mathrm{V}=2,5 \mathrm{~cm}$.); los puntos son hederae (1.1) y triangulares. Fue encontrada en las proximidades de la localidad gaditana de El Bosque, junto a algunos restos de edificaciones antiguas, según me comunicó su propietario, aunque no hayamos pasar de esta somera información. Formaba parte de una colección particular donde la vi y fotografié en 1988 (lám. X):

L(ucius)(hed.)Postumius.Optatus

Fortunae.v(otum).s(olvit).l(ibens).m(erito) pavimentum

«Lucio Postumio Optato ofrece a la diosa Fortuna el pavimento de su templo, cumpliendo así su voto merecido y de buen grado»».

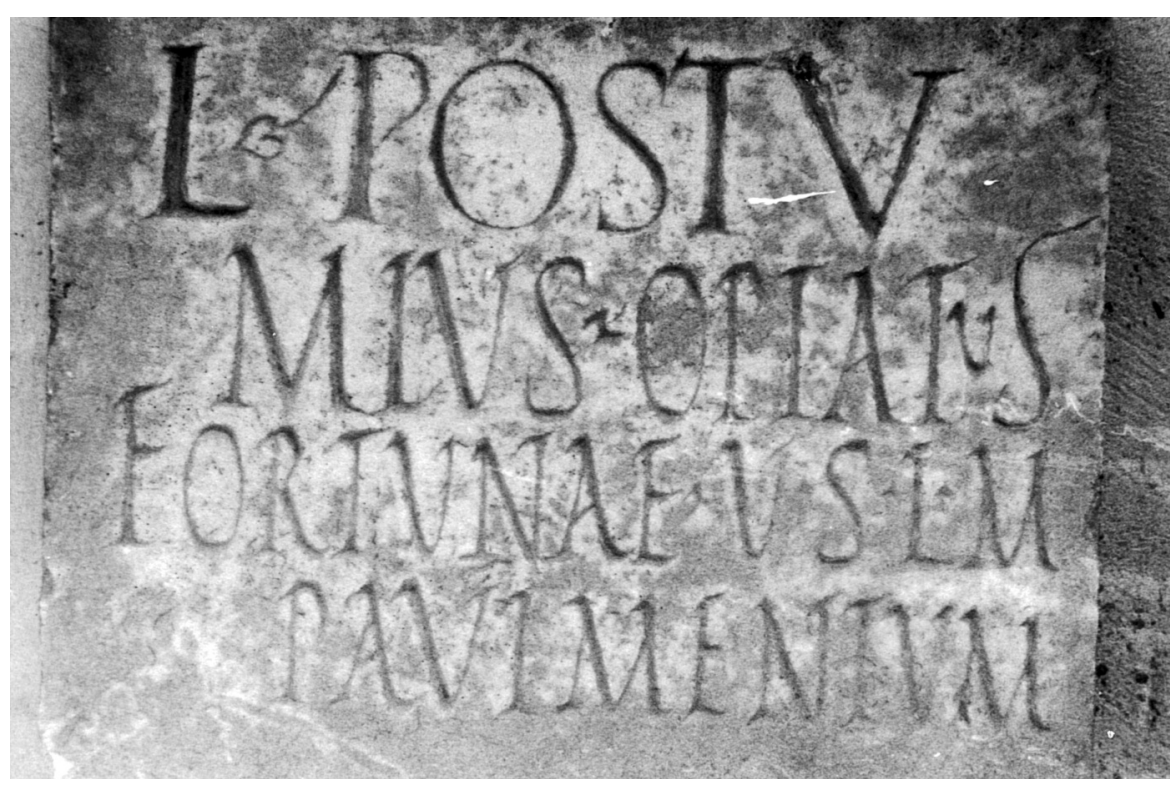

Lámina X. Inscripción de L. Postumius Optatus 
La distribución del texto es muy irregular, especialmente en las 11. 1-2, en la primera, el cuadratario ha colocado el texto en el centro de la cara epigráfica con grandes letras, y en la segunda ha dejado un espacio a la izquierda, en tanto que las letras se le juntan al final y tiene que escribir una $\mathrm{V}$ diminuta. Las letras son capitales cuadradas, de grabado profundo y bella ejecución en la 1.1, y algo más estilizadas en las restantes, incluso en la segunda parte del nomen Postu/mius, los trazos horizontales son cortos, y en la E y F ligeramente curvados hacia arriba, el ojo de la P abierto, el travesaño de la $\mathrm{A}$ inclinado, los ángulos de la $\mathrm{V}$ y M ligeramente redondeados, etc.

\section{- Comentario}

Se trata, pues, de una inscripción votiva, en la que Lucio Postumio Optato ha construido y dedicado el pavimento de un templo a la diosa Fortuna. El culto a esta divinidad tiene amplia representación en la epigrafía hispana, aunque normalmente acompañado del epíteto Augusta. Este tipo de dedicación no es frecuente hasta el punto de que tan sólo encontramos en los repertorios epigráficos sendos ejemplos en Carthago Nova e Hispalis y un probable tercero de El Burgo del Ebro (Zaragoza) (CIL II 5931 = HEp. 12221; HEp. 13, 630 (= 25283); HEp 11, 2001, 621).

Aunque la escasa precisión en la localización del hallazgo dificulta su adscripción a una ciudad antigua determinada, la proximidad de las Cabezas de Hortales, donde se ubica el yacimiento de Iptuci, apenas $6 \mathrm{~km}$. en dirección suroeste, nos inclina a considerar que el dedicante pertenecía realmente a este municipio, aunque es cierto que tenemos atestiguado en Ocurri (Ubrique), una ciudad situada a unos $14 \mathrm{~km}$. de El Bosque en dirección sureste, un C. Postumius Optatus, que ofrece determinados honores al municipio en homenaje a su hija Postumia C.f. Honorata Barbesulana, sacerdos divarum Augustarum (CIL II 1338; IRPC 531) e incluso un poco más alejado encontramos en Carissa Aurelia un L. Postumius Silo, que ofrece cuatro cipos en recuerdo de su amigo L. Fabius L.f. Gal Severus (CIL II 1367; IRPC 97). Por todo ello, si bien seguimos considerando lo más probable su pertenencia a Iptuci, dejamos abierta la posibilidad de que lo sea a alguna de esas otras dos ciudades.

Plinio (Nat.3.1.15) menciona a Iptuci entre las ciudades estipendiarias del convento Gaditano. El hallazgo en las Cabezas de Hortales, término de Prado del Rey, de una inscripción en la que se menciona un ordo Iptucitanorum y de una tabula patronatus en la que el senatus populusque Iptucitanorum realiza el año 31 d.C. un hospitium con la colonia Vcubi Claritas Iulia (CIL II 1923; IRPC 501, 503) confirman el emplazamiento de esta ciudad en el potente yacimiento situado en lo alto de la colina (Tovar 1974, pp.58-59).

La mención del senatus populusque Iptucitanorum no implica que esta ciudad hubiese alcanzado ya el año 31 d.C. el status de una ciudad privilegiada, y el hecho de que figure en las listas de Plinio como ciudad estipendiaria nos lleva a pensar que alcanzaría el estatuto municipal en época flavia. No obstante, los legati encargados de la ejecución del hospitium son cives Romani o Latini: C. Trebecius Laca[nus], C. Attius Seve[rus], L. Catinius Opt[atus]. Este último gentilicio está también atestiguado en otro epígrafe de Las Cabezas de Hortales (CIL II 5484 = IRPC 502). 
- Fecha: Según el tipo de letras, podemos fechar este epígrafe en la primera mitad del siglo II d.C.

\section{GADES, MUNICIPIUM AUGUSTANUM}

\section{4) INSCRIPCIÓN DE CN. POMPEIUS CLARUS}

Placa de mármol, de color amarillento, en muy buen estado de conservación, que mide $20 \mathrm{~cm}$. de altura, $21 \mathrm{~cm}$. de anchura y $2 \mathrm{~cm}$. de grosor; la altura de las letras oscila entre 2,5 y $3,5 \mathrm{~cm}$.; los puntos son triangulares. Fue encontrada en Cádiz, en fecha y circunstancias desconocidas; se encontraba en poder de un coleccionista de dicha ciudad, donde la vi y fotografié en 1994. El texto de la misma es el siguiente (lám. XI):

Cn(aeus).Pompeius

Clarus

ann(orum).XXV

h(ic).s(itus).e(st).s(it).t(ibi).t(erra).l(evis).

«Gneo Pompeyo Claro, de 25 años aquí está enterrado. Sea para ti la tierra leve».

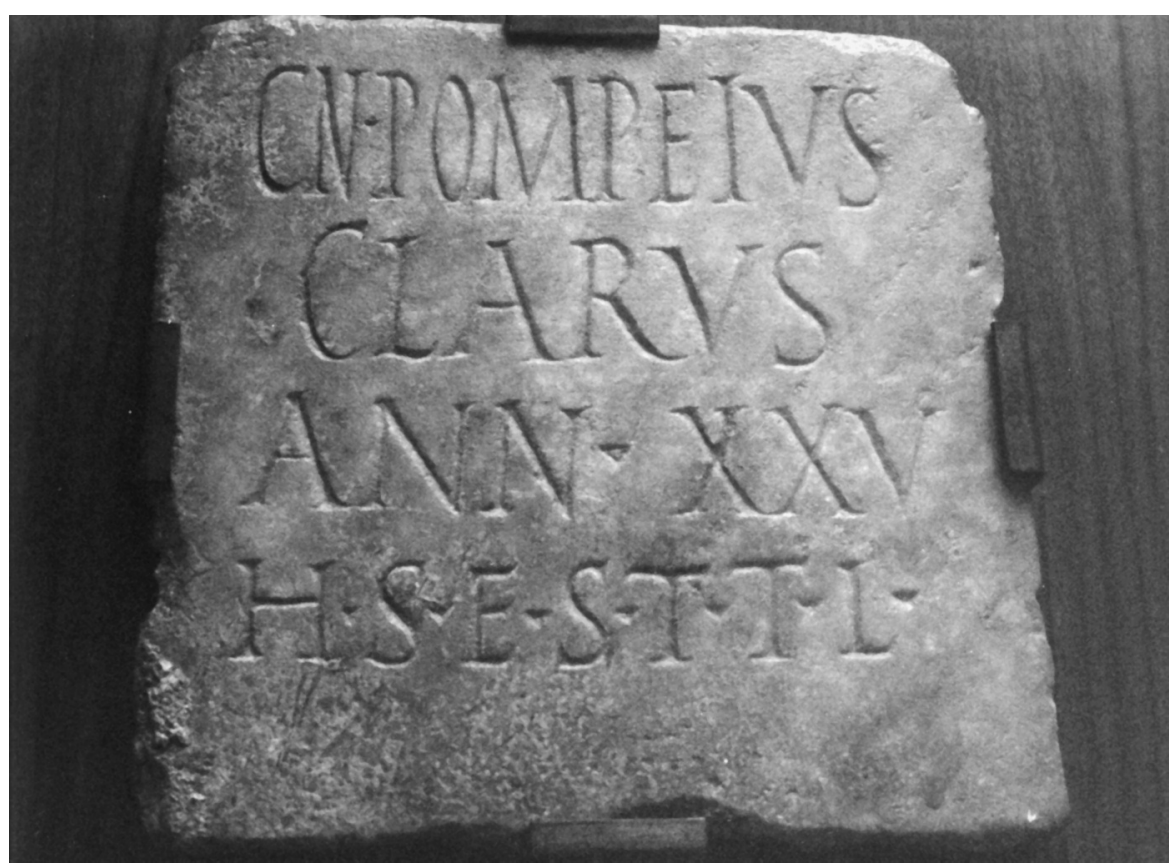

Lámina XI. Inscripción de Cn. Pompeius Clarus 
Hay un intento evidente de cuadrar el texto de forma armónica, aunque las 11. 3-4 desbordan ligeramente los márgenes. Las letras son capitales cuadradas, de bella ejecución y acusados remates, aunque con ciertos rasgos de la actuaria, en especial en la 1.1, donde las letras se alargan ligeramente, sin duda para poder encajar praenomen y nomen del difunto. Hay puntuación irregular al final de la 1.4.

\section{- Comentario}

A pesar de la influencia ejercida por Pompeyo en las tierras de la futura provincia de la Bética, puesta de manifiesto en el apoyo encontrado en las mismas en las guerras civiles contra César, o tal vez precisamente por ello, el praenomen Gn(aeus) está prácticamente ausente de los repertorios epigráficos, hasta el punto de que tan sólo encontramos un testimonio en Torreparedones, probablemente asentamiento de la colonia Virtus Iulia, en un IIVir de la colonia: Cn. Pompeius Cn. f. Gal. Afer aed./ IIvir (CIL II2/5, $420=$ CIL II 1596 (p 871) = HEpOl. 2321). En la propia Gades conocemos también dos Pompeii, pero sus praenomina son Manius y Quintus, respectivamente (CIL II 1867; González 1982, p.263, 363).

Clarus es praenomen bastante habitual, aunque desconocido en la epigrafía gaditana.

Gades es, sin duda, la primera ciudad de Hispania y tal vez de Occidente mencionada en las fuentes históricas (Thouvenot 1973, pp.715-16; Ramírez Delgado 1982), siendo su nombre una transliteración del fenicio 'jgdir' ('jgdr' en las monedas). Los escritores antiguos fijan la fecha de su fundación en torno al año 1100 a.C., pocos años después de la ruina de Troya (Strab.1.3.2; Mela.3.6.46; Vell.2.3.3), lo que convierte a Gades en la ciudad más antigua de Occidente. Sin embargo, los datos proporcionados por las excavaciones no permiten retrotraer su fundación más allá del siglo IX-VIII a.C.

En Gades se encontraba el célebre templo de Herakles, que la tradición clásica situaba a unas 12 millas de la ciudad en la parte oriental de la isla (Strab.3.5.3; Mela. 3.46; Sil.2.17ss.; It.Ant. 408.3; Philostr.Vita Apoll.5.5.); emplazamiento que debemos buscar en la isla de Sancti Petri, que en la antigüedad estaría unida a Gades (Tovar 1974, p.46), en cuyos alrededores, en el mar, se han encontrado importantes restos arquitectónicos, y fragmentos de esculturas (Tovar 1974, p.46; Ramírez Delgado 1982, p.111). El Hércules de Gades aparece representado en las monedas de Adriano y sus sucesores y reaparece años más tarde en las acuñaciones de Postumus (258267 d.C.), en las que lleva la leyenda de Herculi Gaditano (Thouvenot 1973, p.157; Tovar 1974, p.46). El culto del Hércules gaditano se extendió sin duda por la Bética, como ponen de relieve las acuñaciones monetales de diversas ciudades de la misma: Baelo, Lascut, Carmo, Carissa, Iptuci, Callet, etc., e, incluso, la lusitana Salacia.

La fama que llegó a tener en la antigüedad el templo gaditano atrajo a numerosas personalidades que lo visitaron, entre otros, las fuentes mencionan a Aníbal, después de la toma de Sagunto, a Fabio Máximo Emiliano durante sus campañas del año 145 a.C., tal vez Pompeyo, etc. Es muy conocido el relato de que César, después de haber lamentado en el santuario ante una estatua de Alejandro Magno la modestia de su fama, tuvo un sueño incestuoso la noche siguiente que fue interpretado por los adivinos como 
augurio del gran poder que le aguardaba (Dio 37.52.2; 41.24,2; SuET.Caes.7; Plut. Caes.11.3). Es notable que después de la pérdida de su gloria, el santuario de Herakles continúo conservando parte de su antiguo esplendor, como ponen de relieve los versos de Avieno, escritos en torno al 400 d.C. (Ora mar. 271-274).

Los dos Balbos, tío y sobrino, elevaron la influencia de la antigua colonia fenicia, en este momento un oppidum foederatum, a su más alto nivel, en un momento especialmente delicado de la historia de Roma, durante las guerras civiles y el principado de Augusto (Rodríguez Neila 1973). Como hombres de negocio y políticos tomaron el partido de César y luego de Augusto y se convirtieron en las personalidades más relevantes de una ciudad, que era, para algunos, la segunda ciudad en importancia del Imperio, y no sólo en el número de habitantes, superada solamente por Roma, sino también por su riqueza, pues en época de Augusto estaban censados en ella un total de 500 caballeros, número sólo superado por Patavium en Italia (STRAB.3.5.3; Tovar 1974, p.44).

Según la opinión más generaliza (Wilson 1966, p.33, Tovar 1974, p.45; Rodríguez Neila 1980), Gades, que habría sido desde el 206 a.C. una civitas foederata, foedus que el senado renovó el 78 a.C. (Liv.28.23.6 ss.; 32.2.5; Cic. pro Balb. 34; STRAB.3.2.1), alcanzaría el status de municipium civium Romanorum de manos de César el 49 a.C. (Liv.Per.110 (49 a.C.): Gaditanis civitatem dedit; Dıo 41.24.1). La afirmación de Plinio sobre la existencia en Gades de un oppidum civium Romanorum, qui appellantur Augustani Urbs Iulia Gaditana significa, en opinión de diversos historiadores (Grant 1969, pp.171-71; Schönbauer 1954, pp.13-17), entre los cuales me incluyo, que la concesión del derecho de ciudadanía y el status de municipium civium Romanorum fueron dos momentos diferentes, y atribuyen el primero a César y el segundo a Augusto, según demuestran las acuñaciones monetales, donde Agripa es mencionado como $p a$ tronus y parens municipio (González 1984a, pp.92-94).

- Fecha: probablemente primera mitad del siglo II d.C., según el tipo de letra.

\section{ARVA-CANANIA, MUNICIPIA FLAVIA}

\section{5) INSCRIPCIÓN DE PAULA FABIA}

Placa de mármol blanco, partida en dos trozos por una rotura vertical, que ha perdido pequeños fragmentos en su perímetro, aunque sin afectar la lectura del texto; mide $17 \mathrm{~cm}$. de altura, 23 de anchura y $2 \mathrm{~cm}$. de grosor; la altura de las letras oscila entre 1,5 y 1,8 cm; los puntos son pequeñas hederae. Fue encontrada en 1988 en Alcolea del Río, aunque desconozco el lugar exacto y las circunstancias del hallazgo, se encontraba en un anticuario sevillano donde la vi y fotografié en 1990 (lám. XII):

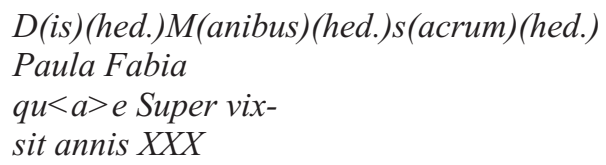




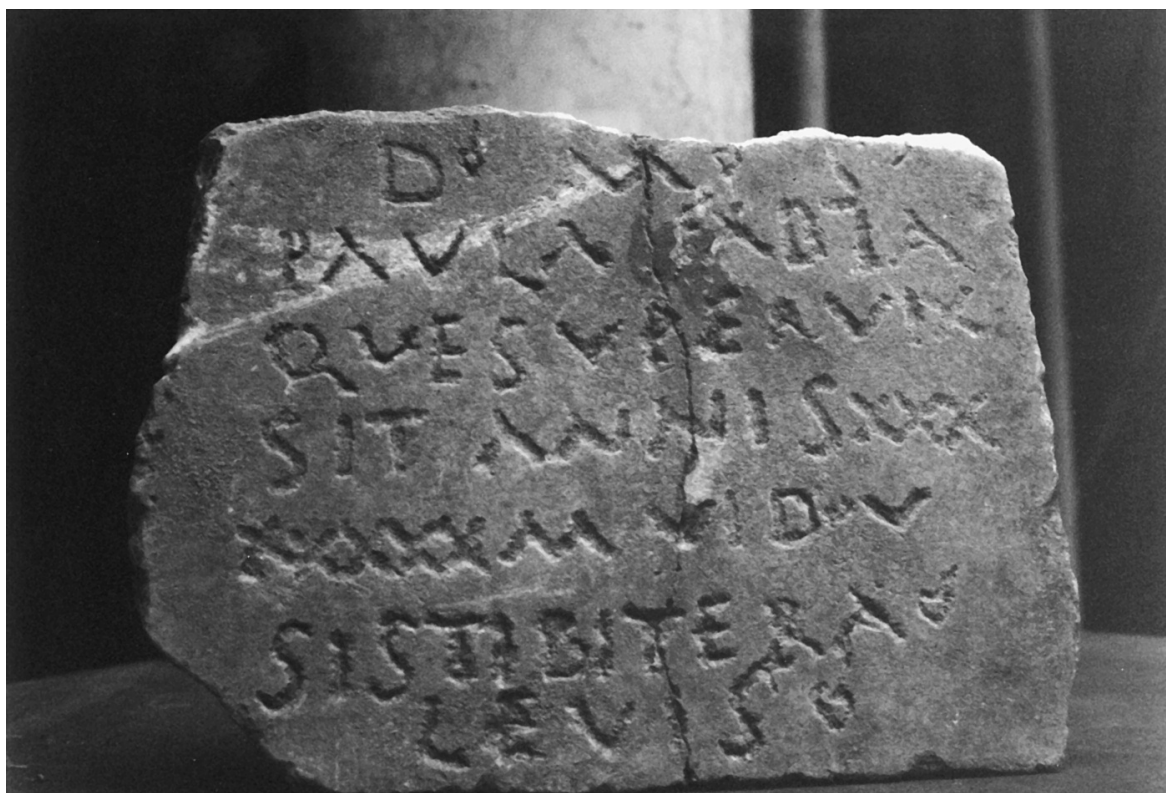

Lámina XII. Inscripción de Paula Fabia

levis(hed.)

«Consagrado a los dioses Manes, Fabia Paula, también llamada Super, vivió ochenta años, seis meses y cinco días. ¡Sea para ti la tierra leve!».

Hay un intento de paginación que podemos considerar conseguido en su margen izquierdo y en las tres primeras líneas del derecho, donde luego se pierde. Las letras son capitales cuadradas muy toscas y de dibujo irregular, así, por ejemplo, la A carece de travesaño, la $\mathrm{N}$ es una especie de A con un trazo inclinado, los ojos de la B abiertos y el de la R cerrado, etc.

Se trata de una pieza desigual, que revela poco conocimiento de las reglas gramaticales y epigráficas, por ejemplo, hay monoptongación de -ae- en que (1.3), simplificación de geminadas en tera (1.6) y doble grafía - xs- para reflejar el fonema de la -xen vix/sit (11. 3-4). Resulta sorprendente la indicación de la edad de la difunta con una acumulación de hasta ocho $\mathrm{X}$, lo que podría parecer una aproximación a la misma, pero esta impresión no se corresponde con la precisa indicación de los meses y los días. También es notable el uso de la segunda persona sis en vez de la tercera sit en la expresión del deseo del lapicida de una muerte tranquila, el desarrollo de dicha fórmula y la ausencia de la ritual H.S.E. Hay puntuación irregular al final de las líneas 1, 6-7.

La onomástica de la difunta presenta, al parecer, cierto desorden en la posición del nomen y el cognomen, si suponemos que Fabia sería el primero y Paula el segundo; 
además también se le atribuye a la difunta el sobrenombre Super, según una conocida costumbre que se generaliza a partir del siglo II d.C. La gens Fabia está ampliamente representada en la epigrafía peninsular en general, y en la Bética en particular. También del cognomen Paula tenemos varios ejemplos tanto en su variante masculina como femenina.

\section{- Comentario}

En el término de Alcolea del Río se localizan dos ciudades romanas bien conocidas: Arva y Canania, que aparecen mencionadas en Plinio (Nat.3.3.11), junto a Celti y Axati, en una serie de ciudades localizadas en las márgenes del Baetis. Arva ha sido localizada, de forma unánime, en El Castillejo, lugar situado a unos 2,5 km. río arriba de Alcolea del Río (Tovar 1974, pp.159-160; Ponsich 1974, pp.154-155). Con frecuencia se ha situado el emplazamiento de Arva, también conocida como Portus Arvensis, en la Peña de la Sal, situada a unos 800 m. al este de El Castillejo (Bonsor 1931, p.28; Callender 1965, p.74), donde se han encontrado restos de construcciones al borde del río, numerosos fragmentos de cerámica y restos de ladrillos y de ánforas, que permiten concluir que estos vestigios corresponden a los suburbios de la ciudad romana de Arva. De Arva conocemos varias inscripciones en las que se la menciona como municipium Flavium Arvense (CIL II 1060, 1064-1066; CILA II.1, 220; 223-225).

Se han conservado hasta nuestros días restos de unas termas romanas con salas abovedadas, piscinas, columnas con capitales corintios, cuyo frigidarium estaba cubierto de mármol. Aún se pueden ver la conducción de agua y el acueducto que unía las termas con la fuente de la Mezquita, aproximadamente a $1 \mathrm{~km}$. al norte de la ciudad. Una pintura mural, llevada por G. Bonsor al Museo de la Necrópolis de Carmona, nos revela la riqueza de sus habitantes. También se han encontrado numerosas inscripciones (CILA II,1, 220-232).

En época romana fue, sin duda, un gran centro productor de ánforas de aceite (Dressel 20), que hicieron necesario la construcción de un portus, que las obras de la carretera Cantillana-Córdoba pusieron en 1890 al descubierto. Las marcas, muy abundantes, revelan una producción considerable de aceite y se extienden desde finales del siglo I hasta comienzos del III d.C.. La totalidad de las marcas reunidas por Bonsor proceden de una trinchera abierta en el flanco de El Castillejo por la carretera a Lora del Río.

Arva alcanzó el status de municipio de derecho Latino en época de los Flavios, según demuestran las inscripciones y la adscripción de sus ciudadanos a la tribu Quirina. No conocemos ningún magistrado municipal, aunque si dos seviros, M. Egnatius Verna y M. Egnatius Venustus, ambos libertos de M. Egnatius Scitius.

Canania aparece mencionada por Plinio con la grafía Canama, que los testimonios epigráficos nos permiten corregir en Canania. En un principio esta ciudad fue localizada en Villanueva del Río, donde se han encontrado diversas inscripciones, aunque recientes hallazgos y excavaciones nos han permitido situarla correctamente en lugar conocido como La Mesa, situada a unos $2 \mathrm{~km}$. al norte de Alcolea del Río (Tovar 1974, p.160; Ponsich 1974, pp.139-142). 
Los hallazgos arqueológicos permiten establecer que Canania era una ciudad muy antigua cuyo origen podría situarse alrededor del siglo VIII a.C.; desgraciadamente, hace varios años, el cerro ha sido traillado y arrasado el yacimiento prácticamente en su totalidad. Entre los objetos salvados, en una excavación de urgencia realizada por Fernando Fernández, se encuentran algunas inscripciones, restos de estatuas y un mosaico. Bonsor menciona la existencia de una cisterna circular de unos 3,50 m. de diámetro, en buen estado de conservación, y conservado gracias a que ha servido de capilla hasta comienzos del siglo XIX (Bonsor 1901, pp.840-41).

El nombre de la ciudad está atestiguado en una inscripción encontrada en Sevilla, en la que se menciona a unos lyntrarii Cananienses, Oducienses et Naevenses (CIL II 1182 = CILA II,1, 32). También está atestiguado el nombre de la ciudad en sendas inscripciones, en una de las cuales, un tal L. Attius Vetto, flamen et IIvir m(unicipum) m(unicipii) Flavi Canan(iensis), en nombre propio, en el de sus hijos y de su nieta ofrece un pórtico de mármol, construido en suelo propio, luego de haber ofrecido unos juegos escénicos y dado un banquete público (CIL II 1074; CILA II,1, 234; EE VIII 91; CILA II,1, 239), probablemente como munus obligatorio al tomar posesión del sacerdocio, y en la otra, el ordo mun(icipii) [m(unicipii) F(lavii)] Canan(iensis) ha decretado en honor de L. Thacius Lupus diversos honores fúnebres y una estatua pedestre.

Estos dos epígrafes nos demuestran claramente que Canania alcanzó el status municipii en época Flavia, como consecuencia de la concesión por Vespasiano del ius Latii a Hispania. Efectivamente sus habitantes estaban inscritos en la tribu Quirina, propia de las fundaciones Flavias (Wiegels 1985, p.25).

- Fecha: Por todas las características apuntadas, especialmente el tipo de letra y la tosquedad de las mismas, podríamos fechar este epígrafe en el siglo III.

\section{IPTUCI}

\section{6) INSCRIPCIÓN DE AELIA SEVERA}

Ara de mármol blanco con doble moldura de base y coronamiento, sobre la que se encuentra un frontón triangular, y a ambos lados y en el interior del frontón sendas flores de cuatro pétalos con botón central, en la parte superior tiene un focus; tiene grabados en su costado izquierdo un bello simpulum y en derecho una patera; ha sufrido fuerte desgaste en su superficie, especialmente en la cara epigráfica, y perdido un pequeño fragmento en su ángulo superior izquierdo; los signos de puntuación son redondos. Mide 1,60 m. de altura por $0,75 \mathrm{~m}$. de anchura; la cartela $0,70 \mathrm{~m}$. por 0,60 $\mathrm{m}$. Fue encontrada en el cortijo de Barbacena, en el término municipal de Escacena del Campo, al realizarse unas faenas agrícolas, y allí se encuentra adosada a un muro del mismo. Debo la foto del epígrafe a la amabilidad de Don Francisco de Paula Pérez Sindreu (lám. XIII): 


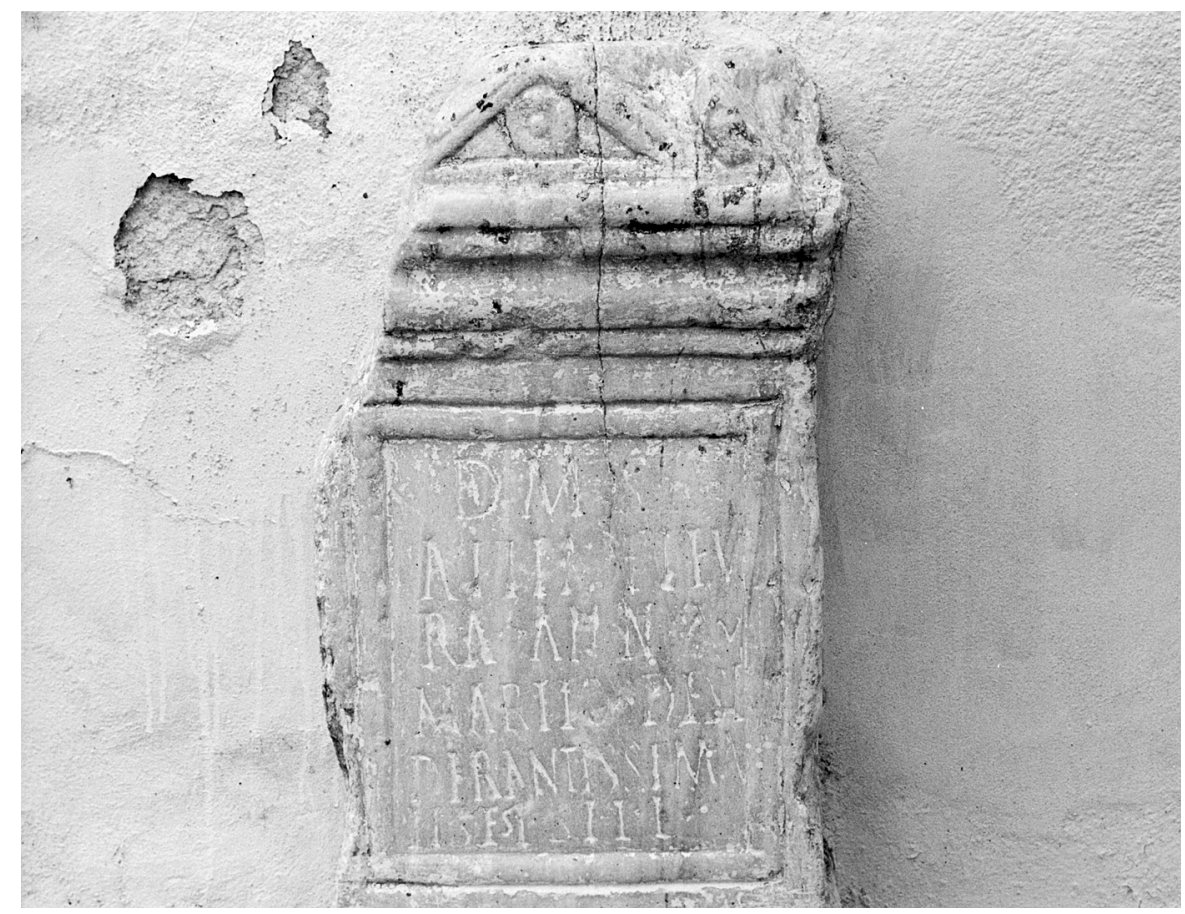

Lámina XIII. Inscripción de Aelia P.f. Severa

\author{
ra.ann(orum). $X X$ \\ marit $\mid$ us $\mid$. desi- \\ 5 derantissimus. \\ H(ic).s(ita).est.s(it).t(ibi).t(erra).l(evis).
}

«Consagrado a los dioses Manes. Elia Severa, hija de Publio, de 20 años de edad, aquí está enterrada. ¡Sea para ti la tierra leve! Un marido que la echa muchísimo de menos».

La paginación de ambos márgenes está muy lograda, hasta el punto de que para lograrla el lapicida se ha visto obligado a reducir el tamaño de algunas letras finales de línea. Las letras son capitales cuadradas en la 1.1, y actuarias en las restantes, con grabado un tanto irregular y bastante tosco, así, por ejemplo, la A carece de travesaño, los trazos horizontales de la T, E, L están muy poco marcados, la $H$ tiene los trazos verticales diferentes y la $\mathrm{S}$ de EST es más pequeña, y la distribución del texto en la cartela es muy irregular. El nominativo maritus ha sido manipulado en época posterior para escribir una $-\mathrm{O}$.

\title{
- Comentario
}

Los miembros de la gens Aelia están presentes en gran número de ciudades hispanas, siendo una de las más representadas en las ciudades de la Bética, con especial 
recuerdo de la vecina Itálica. También el cognomen tiene amplia presencia en los repertorios epigráficos.

En los itinerarios (It. Ant. 432.2; An. Rav., 317.13: Tusci o Tucci?) se menciona una ciudad de nombre Tucci, a occidente de Italica, en la vía que desde la desembocadura del Guadiana se dirigía a Emerita Augusta, a 22 millas de Illipula y 18 millas de Italica. Ptolomeo (2.4.10) también la menciona a unas 76 millas de Italica (sin duda un error), pero a la misma distancia que hay en el It. Ant. entre Onoba y Tucci.

A pesar de la afirmación de Schulten que consideraba su emplazamiento desconocido, su localización en el despoblado de Tejada la Vieja, término municipal de Escacena del Campo, está asegurada (Thouvenot 1973, p.488; Tovar 1974, p.167). Hübner (CIL II, p.166), si bien reconoce que en el despoblado de Tejada se encuentran con frecuencia las monedas con leyenda IPTVCI, no admite una identificación entre la ciudad que acuñaba estas monedas y la Tucci de los Itineraríos; posteriormente (CIL II, p.842), rechaza la afirmación de Kubitschek (1882, p.148) de que la inscripción del duoviro Cornelius Senex (CIL II 1258; CILA I, 84), no podía ser de Osset, pues la tribu de ésta era la Galeria y no la Quirina. Este parecer de Hübner ha sido seguido por Galsterer, que lo utiliza erróneamente como ejemplo de la existencia de la tribu Quirina en una ciudad de fundación julio-claudia (Galsterer 1971, p.46). En este lugar se encuentran las fuentes, de donde partía un acueducto que abastecía de agua a Itálica.

La adscripción de Q.Cornelius Senex, IIvir quater, a la tribu Quirina nos permite suponer que Iptuci alcanzó el status de municipio, como tantas otras ciudades de la Bética, en época de los Flavios, con motivo de la concesión a Hispania del ius Latii por Vespasiano el 73-74 d.C.

- Fecha: Podemos fechar la inscripción, según sus características externas y el tipo de letra en la segunda mitad del siglo II d.C.

\section{REFERENCIAS BIBLIOGRÁFICAS}

BONSOR, G. (1901), «Los pueblos antiguos del Guadalquivir y las alfarerías romanas», RABM $5,840-41$.

Bonsor, G. (1931), The archaeological expedition along the Guadalquivir, New York, Hispanic Society of America.

Caballos Rufino, A. (2006), El nuevo bronce de Osuna y la política colonizadora romana, Sevilla, Univ. de Sevilla.

Callender, M.H. (1965), Roman Amphorae, Londres, Oxford University Press.

CAmpos CARRASCO, J.M. (1989), «Análisis de la evolución espacial y urbana de Urso», en GonZÁlez, J. (ed.), Estudios sobre Urso colonia Iulia Genetiva, Sevilla, Ediciones Alfar, pp.99-111.

CILA (1991-1996.), Corpus de inscripciones latinas de Andalucia, vol. II, tomos I-IV, Sevilla, Consejería de Cultura y Medioambiente.

GALSTERER, H. (1971), Untersuchungen zum Römischen Städtewesen auf der Iberischen Halbinsel, Berlín, Walter de Gruyter. 
Galsterer, H. - KRÖLl, B. (1972), «Untersuchungen zu den Beinamen und der Rechts-stellung von Städte des Imperium Romanum», ES 9, 49-61.

Galsterer, H. - KRÖLl, B. (1975), «Zu den spanischen Städteliste des Plinius», AEArq., 48, 124.

GONZÁlEZ FERNÁNDEZ, J. (1982), Inscripciones romanas de la provincia de Cádiz (IRPC), Cádiz, Diputación Provincial.

GONZÁLEZ FERNÁNDEZ, J. (1984), «Itálica, municipium iuris Latini», MCV 20, 21-31.

GonZÁlez fERnÁNDEZ, J. (1984a), «Tabula Siarensis, Fortunales Siarenses et municipia civium Romanorum», ZPE 55, 55-101.

GonZÁlez FernáNDEZ, J. (1991-1996), Corpus de inscripciones Latinas de Andalucía, vol. II, tomos I-II, Sevilla 1991, III-IV, Sevilla 1996 (= CILA).

Grant, M. (1969), From Imperium to Auctoritas. A Historical Study of the aes coinage in the Roman Empire 49 B.C.-A.D. 14, 2a ed. Cambridge, University Press.

Kajanto, I. (1965), The Latin cognomina, Helsinki, Liro.

Kubitscheck, W. (1882), De Romanorum tribuum origine et propagatione, Viena, Universität Wien III.

Le Roux, P. (1982), L'Armée romaine et l'organisation des provinces ibériques d'Auguste a l'invasion de 409, París, Diffusion De Boccard.

PACHÓn Romero, A. (2011), «De la Urso tardo-republicana a la colonia Genetiva Iulia. Un análisis desde la historiografía y la arqueología», en GonZÁlez FERnÁndEZ, J.- SAQUETE, J.C. (edd.), Colonias de César y Augusto en la Andalucía romana, Roma, L'Erma di Bretschneider, pp. 187-222.

RAmírez DElgado, J.R. (1982), Los primitivos núcleos de asentamiento en la ciudad de Cádiz, Ayuntamiento.

Rodríguez Neila, J.F. (1973), Los Balbos de Cádiz. Dos españoles en la Roma de César y Augusto, Sevilla, Universidad Sevilla.

Rodríguez Neila, J.F.. (1980), El municipio romano de Gades, Cádiz, Diputación Provincial.

Schönbauer, E. (1954), Municipia und coloniae in der Prinzipatszeit, Viena, Anz. Oesterr. Ak. Wiss.

Sillierès, P. (1990), Les voies de communication de l'Hispania Méridionale, París, Diffusion De Boccard.

Solin, H. (2003), Die griechischen Personennamen in Rom, $2^{\circ}$ ed. Ein Namenbuch. I, II, III, Zweite, vollig neu bearbeitete Auflage. CIL, Auctarium n.s. 2,, Berlín-New York.

Thouvenot, R. (1973), Essai sur la province Romaine de Bétique, 2ª ed., París, E. De Boccard.

Tovar, A. (1974), Iberische Landeskunde, Zweiter Teil: Die Völker und die Städte des antiken Hispanien, Bd. I. Baetica, Baden-Baden, Körner.

Wiegels, R. (1985), Die Tribusinschriften des Römischen Hispanien, Berlín, W. de Gruyter.

WiLson, A.J.N. (1966) Emigration from Italy in the Republican age of Rome, Manchester, Manchester University Press.

Wiseman, F.J. (1956), Roman Spain, Londres, Oxford University Press. 